\title{
KAJIAN KONSEP LINKAGE PADA KAWASAN TOD (TRANSIT ORIENTED DEVELOPMENT) WEST KOWLOON, HONG KONG
}

\author{
Muh Fikry Nursyawal1*, Ari Widyati Purwantiasning² \\ Program Studi Teknik Arsitektur, Universitas Muhammadiyah Jakarta ${ }^{1}$ \\ Program Studi Teknik Arsitektur, Universitas Muhammadiyah Jakarta ${ }^{2}$ \\ e-mail: *1nursyawalmuhammadfikri@gmail.com, ${ }^{2}$ arwityas@yahoo.com
}

\begin{abstract}
Abstrak_ Pertumbuhan penduduk yang semakin hari semakin bertambah mengakibatkan kepadatan penduduk pada suatu wilayah. Perkotaan merupakan salah satu wilayah yang signifikan terkena dampak dari kepadatan penduduk tersebut. TOD (Transit Oriented Develompent) merupakan konsep kawasan perkotaan yang memiliki visi untuk menjadi solusi terhadap dampak dari kepadatan penduduk. Kawasan TOD merupakan kawasan perkotaan yang relatif kompleks dan rumit. Kawasan ini memiliki kecenderungan membuat orang-orang merasa bingung dan tersesat dalam beraktivitas atau bergerak. Penelitian ini membahas tentang elemen-elemen linkage visual berdasarkan teori linkage visual Roger Trancik dan menganalisis penerapan terhadap kawasan TOD. Hasil penelitian disimpulkan bahwa elemen-elemen linkage visual yang teridentifikasi cenderung mengarahkan (membentuk pola) dan mempertegas aktivitas dengan titik pusat kawasan TOD.
\end{abstract}

Kata Kunci: Kawasan; Linkage Visual; TOD (Transit Oriented Development)

Abstract_Population growth is increasingly increasing, resulting in overcrowding in a region. Urban is one area that is significantly affected by population density. TOD (Transit Oriented Development) is an urban area concept that has the vision to be a solution to the impact of population density. The TOD area is a relatively complex and complicated metropolitan area. This area has a tendency to make people feel confused and lost in activities or moving. This study discusses the elements of visual linkage based on Roger Trancik's visual linkage theory and analyzes the application to the TOD region. The results of the study concluded that the details of identified visual linkage tended to direct (form patterns) and reinforce activities with the focal point of the TOD region.

Keyword: District, Linkage Visual, TOD (Transit Oriented Development)

\footnotetext{
${ }^{1}$ Program Studi Teknik Arsitektur, Universitas Muhammadiyah Jakarta
} 2 Program Studi Teknik Arsitektur, Universitas Muhammadiyah Jakarta 


\section{PENDAHULUAN}

Pertumbuhan penduduk yang semakin hari semakin bertambah mengakibatkan kepadatan penduduk pada suatu wilayah. Perkotaan merupakan salah satu wilayah yang signifikan terkena dampak dari kepadatan penduduk tersebut. Kemacetan, turunnya kualitas lingkungan hidup, munculnya kawasan-kawasan kumuh pada kota dengan hunian-hunian yang tidak layak huni merupakan sebagian dari dampak yang dipicu oleh kepadatan penduduk. TOD (Transit Oriented Develompent) merupakan konsep kawasan perkotaan yang memiliki visi untuk menjadi solusi terhadap dampak dari kepadatan penduduk.

Kawasan TOD merupakan kawasan perkotaan yang relatif kompleks dan rumit. Kawasan ini memiliki kecenderungan membuat orang-orang merasa bingung dan tersesat dalam beraktivitas atau bergerak. Jika hal tersebut terjadi maka, tidak menutup kemungkinan rasa aman dan nyaman yang merupakan buah hasil dari prinsip-prinsip TOD tidak dapat terealisasi. Adapun prinsipprinsip TOD yang kontradiktif dengan hal tersebut yakni berjalan kaki (walk), bersepeda (cycle), menghubungkan (connect), angkutan umum (transit), pembaruan (mix), memadatkan (densify), merapatkan (compact), beralih (shift).

Berdasarkan permasalahan di atas, peneliti beranggapan perlu adanya kajian Konsep linkage pada kawasan TOD. untuk mempertegas alur pergerakan kegiatan masyarakat pengguna. Adapun pengertian Konsep linkage adalah penekanan terhadap konektivitas pergerakan yang terjadi pada beberapa bagian kawasan kota seperti hubungan sebuah tempat dengan tempat lain dalam sebuah kota (Trancik 1973). Maka dari itu penulis melakukan penelitian yang berfokus pada keterkaitan konsep lingkage dengan kawasan TOD dan melihat implementasi dari konsep linkage pada kawasan TOD di daerah Kowloon.

\section{A. Linkage}

Linkage artinya berupa garis semu yang menghubungkan satu elemen dengan elemen yang lainnya, nodes yang satu dengan yang lain dan atau kawasan yang satu dengan lainnya. Garis ini bisa berupa jaraingan jalan, jalur pedestrian, ruang terbuka yang berbentuk segaris atau sebagainya. Linkage Visual memiliki lima elemen yang dapat membentuk hubungan secara visual diantaranya adalah elemen visual garis (line), koridor (corridor), sisi (edge), sumbu (axis), dan irama (rythm). Teori linkage merupakan bentukan kota yang tidak lepas dari adanya hubungan atau jaring-jaring sirkulasi (network circulation). Hubungan yang ada berupa jalan, jalur pedestrian, ruang terbuka yang berbentuk garis linier ataupun bentuk-bentuk secara fisik menjadi penghubung antar bagian kota/kawasan. Dalam perancangan, teori 
penghubung ini sangat berguna sebagai salah satu titik acuan dalam mengorganisasi sistem pergerakan dalam suatu kawasan (Trancik 1973). Teori linkage merupakan sistem ide pernyataan yang diambil dari garis-garis yang menghubungkan antar unsur bagian kota. Penekanan lebih kepada diagram sirkulasi daripada diagram ruang. Dinamika sirkulasi menjadi generator bentuk kota, dengan penekanan pada koneksi dan pergerakan tetapi kebutuhan akan ketentuan ruang kurang diperhatikan (Djokomono dan Nugroho 2000).

Linkage merupakan teori yang menekankan pada hbubungan pergerakan yang terjadi di beberapa bagian kawasan kota seperti hubungan sebuah tempat dengan tempat lain dalam sebuah kota (Nugroho, Purwantiasning, dan Hantono 2017). Dari teori figure/ground terdapat keterbatasan dikarenakan pendekatan ini sering mengarah ke gagasan ruang perkotaan yg bersifat dua dimensi saja dan perhatiannya terhadap ruang perkotaan statis, artinya dinamika hubungan secara arsitektural antara berbagai kawasan kota belum diperhatikan dengan baik. Pada teori linkage perhatian lebih mengarah kepada hubungan sebuah tempat dengan yang lain dari berbagai aspek sebagai suatu generator perkotaan (Umanailo et al., n.d.)

\section{B. Kawasan}

Menurut Kamus Besar Bahasa Indonesia (KBBI), kawasan merupakan daerah tertentu yang mempunyai ciri tertentu, seperti tempat tinggal, pertokoan, industri, bisnis, komersial dan sebagainya. Kawasan merupakan suatu daerah yang memiliki karakter tertentu. Menurut (Kostof 1991) Kota adalah leburan dari bangunan dan penduduk, sedangkan bentuk kota pada awalnya adalah netral tetapi kemudian berubah sampai hal ini dipengaruhi dengan budaya tertentu. Kawasan kota adalah suatu wilayah tempat tinggal manuasia yang merupakan manifestasi dari penrencanaan dan perancangan yang dipenuhi oleh berbagai unsur seperti bangunan, jalan, ruang terbuka hijau dan ruang terbuka publik (Jackson 1984). Berdasarkan pendapat para ahli, penuli berkesipulan bahwa, kawasan kota merupakan sebuah wilayah yang menjadi pusat aktivitas yang memiliki kepadatan penduduk yang relatif tinggi dan memiliki berbagai macam karakter atau sifat penduduk yang berbeda-beda. Kawasan kota juga merupakan pusat dari kegiatan pemerintahan dan bisnis oleh sebab itu kawasan kota setidaknya terdapat fasilitas-fasilitas publik yang dapat menunjang aktivitas-aktivitas pada suatu kawasan. 


\section{TOD (Transit Oriented Development).}

Transit Oriented Development atau yang dikenal dengan singkatan TOD merupakan salah satu konsep kawasan yang bertujuan untuk menciptakan lingkungan yang mengurangi ketergantungan tinggi terhadap kendaraan pribadi dan mendorong penggunaan transportasi publik (bus, kereta api, angkutan umum, dan sebagainya) melalui promosi aksesibilitas dan mobilitas yang baik menuju titik-titik transit (stasiun, terminal, halte/bus stop). TOD telah dikenal luas sebagai konsep yang menjawab kebutuhan area transit. Diantara manfaat dari TOD adalah penurunan penggunaan mobil dan pengeluaran keluarga untuk transportasi, peningkatan pejalan kaki dan pengguna transit, menghidupkan kembali kawasan pusat kota, peningkatan densitas dan intensitas,penghematan beban pengembangan untuk parkir, serta peningkatan nilai properti dan berbagai kegiatan disekita rtransit, hingga perbaikan kualitas lingkungan dan komunitas (Toding, Jinca, and Wunas, n.d.). Transit Oriented Development (pengembangan kawasan berbasis transit) telah menjadi model penataan kawasan untuk mereduksi kemacetan dan kesemrawutan kota yang memberikan dampak positif terhadap peningkatan kualitas lingkungan (Raniasta, Ikaputra, and Widyastuti 2016). Transit Oriented Development (TOD) adalah salah satu konsep tata ruang perkotaan yang efektif untuk dapat menyelesaikan masalah kemacetan lalulintas pada kawasan perkotaan (Bachtiar Arief et al. 2015). Konsep TOD bertujuan untuk mengembangkan kawasan dengan sistim transportasi massal yang saling terkait dan terintegrasi, dengan menggunakan prinsip-prinsip TOD dalam menata kawasan (Firdaus, Purwantiasning, danPrayogi 2018)

Gagasan konsep TOD (Transit Oriented Developmetn) bertujuan untuk memberikan alternatif dan pemecahan bagi permasalahan pertumbuhan metropolitan yang cenderung pada pola Auto Oriented Development. Dengan membuat fungsi campuran (mixed-use) yang kompak dalam jangkauan lima hingga lima belas menit berjalan kaki pada area-area transit, diharapkan didapatkan beberapa manfaat. Di antaranya, terjadi internalisasi pergerakan antara hunian, perkantoran dan fungsi-fungsi lain dalam sebuah distrik yang tersentralisasi (Priadmaja, Anisa, dan Prayogi 2017). Konsep TOD merupakan suatu pendekatan rekayasa ruang yang terfokus pengembangannya di sekitar titik transit. Ruang yang dikembangkan nantinya memiliki ciri yakni densitas yang tinggi, diversitas yang beragam serta desain kawasan yang ramah terhadap pejalan kaki (Arsyad dan Handayeni 2018). Pengembangan suatu kawasan TOD dapat menciptakan konektivitas yang kuat antar daerah, serta dapat menekan penggunaan kendaraan pribadi sehingga beban kota induk menjadi berkurang (Octarino, n.d.). TOD (Transit Oriented Development) merupakan gagasan alternatif yang bertujuan mengatasi permasalahan kemacetan di kota-kota besar. Membuat kawasan yang berkonsep TOD mempunyai banyak manfaatnya jika desain 
tersebut tepat dalam proses mengkaji terlebih dahulu. Salah satunya yaitu, penataan massa bangunan di dalam sebuah kawasan yang ingin dijadikan kawasan TOD. TOD menyiratkan proses perencanaan dan perancangan yang berkualitas tinggi dari pola tata ruang dan wilayah untuk mendukung, memfasilitasi, dan memprioritaskan tidak hanya penggunaan angkutan umum, tapi juga moda transportasi yang paling mendasar yaitu berjalan kaki dan bersepeda.

\section{METODE}

\section{A. Jenis Penelitian}

Agar penelitian tepat sasaran dan sesuai dengan tujuan yang telah ditetapkan, maka metode yang digunakan dalam penitian ini adalah metode Deskriptif naratif menggunakan studi kasus sebagai pendekatannya untuk menjawab permasalahan yang diangkat dalam penelitian ini. Pendekatan studi kasus menurut (Yin 2004) studi kasus digunakan sebagai suatu penjelasan komprhensif yang berkaitan dengan berbagai aspek seseorang, suatu kemlompok, organisasi atau situasi kemasyarakatan yang diteliti dan ditelaah dengan dalam. Tujuan dari penelitian ini adalah untuk mengungkapkan kejadian atau fakta, keadaan, fenomena, dan keadaan yang terjadi saat penelitian berlangsung dengan menyuguhkan apa yang sebenarnya terjadi. Tujuan dari penelitian ini adalah tidak hanya sekedar untuk menjelaskan secara menyeluruh masalah yang akan diteliti dan diamati, namun juga ada tujuan lainnya. Tujuan dari penelitian deskriptif kualitatif akan menjadi pedoman bagi kita ketika akan melakukan suatu penelitian

\section{Objek penelitian}

Dalam penelitian ini, peneliti mengambil lokasi studi kasus yang merupakan kawasan TOD, yakni kawasan TOD Kowloon di Hongkong.

\section{Teknik analisis data}

Analisis data Kualitatif merupakan upaya yang digunakan untuk mengkoordinasi dan mengolah data agar data yang telah diperoleh dapat dikelola menjadi suatu sehingga dapat lebih mudah untuk dipelajari. Adapun tahapan dalam menganalisis data sebagai berikut :

Tahapan analisis data (Sugiyono 2006) yaitu:

a. Pengumpulan Data dilakukan dengan cara observasi dan tela'ah dokumen.

b. Penyajian data telah dirangkum untuk menggambarkan bentuk-bentuk atau pengolahan data yang telah didapatkan di lapangan. 
c. Penarikan kesimpulan, setelah data-data telah diuraikan maka peneliti akan memberikan kesimpulan penelitian. Pada tahap ini akan ditarik kesimpulan dari data-data yang sudah diperoleh dengan melihat proses yang terjadi di lapangan.

d. Membuat kesimpulan, pada tahap akhir dari penelitian ini, peneliti dapat menarik kesimpulan dari semua tahap penelitian yang sudah dilakukan. Kesimpulan pada penelitian harus menjawab rumusan masalah yang ada dan mengacu pada tujuan penelitian.

\section{HASIL DAN PEMBAHASAN}

Pada sub bab ini, peneliti akan menyampaikan hasil dari kunjungan dari ke tiga objek kawasan yang telah dipilih sebelumnya. Selanjutnya hasil yang telah didapatkan kemudian dianalisis dan dibahas berdasarkan penelitian deskriptif kualitatif. Tujuannya ialah untuk mengungkapkan kejadian atau fakta, keadaan, dan fenomena yang terjadi saat penelitian berlangsung dengan menyuguhkan apa yang sebenarnya terjadi.

\section{A. Gambaran Umum Kawasan TOD (Transit Oriented Development)}

Kowloon merupakan kawasan perkotaan yang terletak di Hong Kong. Secara geografis Kowloon terletak di bagian Selatan Hong Kong. Kawasan Kowloon merupakan kawasan yang sangat berkembang sehingga banyak sekali bangunan-bangunan tinggi. Kawasan Kowloon juga merupakan destinasi favorit para turis-turis mancanegara karena banyaknya objek destinasi yang unik dan ditunjang oleh transportasi umum yang baik dan juga karena letak Avenue of Star yang terletak pada pinggir kawasan Kowloon.

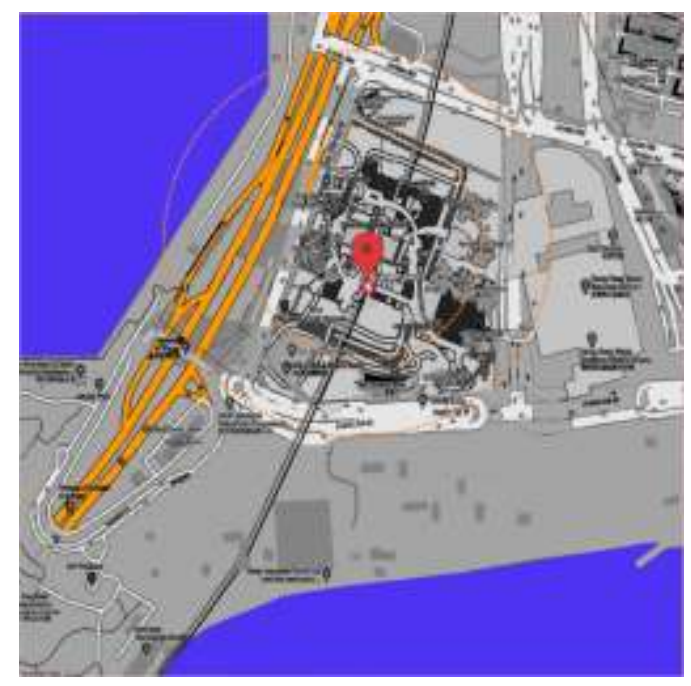

Gambar 1. Peta Lokasi Kawasan Kowloon Sumber: Dokumen Pribadi 


\section{Zonasi kawasan}

Kawasan Kowloon meupakan kawasan yang relatif sangat padat. Berbagai macam jenis kegiatan terdapat pada kawasan ini. Hal ini dapat dilihat dari bangunan-bangunan yang ada pada kawasan Kowloon. Pada gambar 2, merupakan gambar peta zonasi kawasan Kowloon.

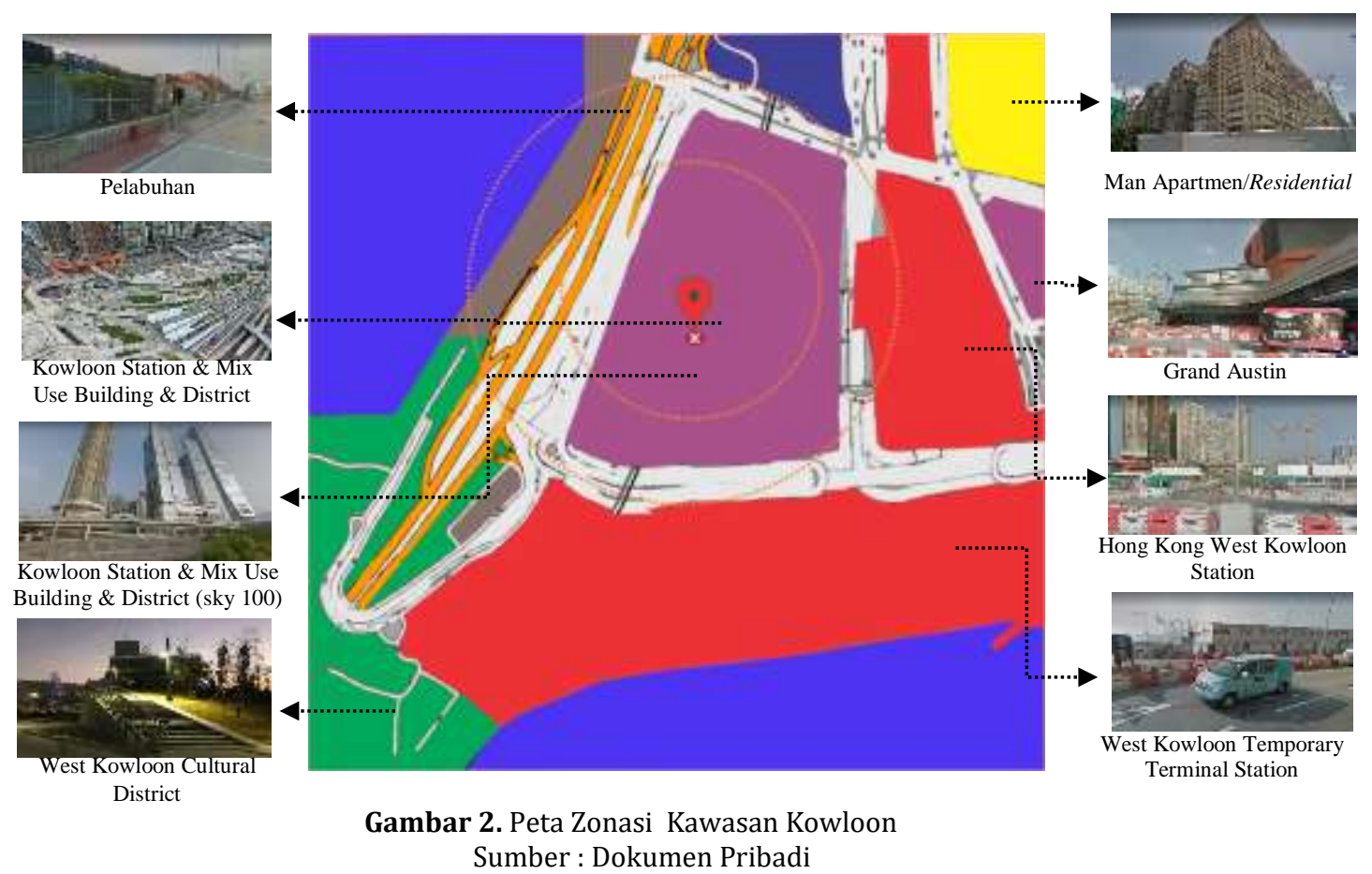

Pada peta zonasi kawasan Kowloon terlihat berbagai jenis bangunan diantaranya, bangunan campuran (ungu), perkantoran (biru tua), stasiun dan terminal (merah), ruang terbuka publik dan ruang terbuka hijau (warna hijau), permukiman/residential (kuning), dan pelabuhan (coklat).

\section{Jaringan Jalan.}

Pada kawasan TOD Kowloon terdapat beberapa jaringan jalan, diantaranya Jaringan jalan untuk kendaraan bermotor, jaringan jalan untuk pejalan kaki, dan jaringan jalan untuk sepeda. Berikut gambar peta jaringan jalan yang terdaoat di kawasan Kowloon; 


\begin{tabular}{r|r|} 
Kajian Konsep Linkage pada Kawasan TOD & $\begin{array}{r}\text { Muh Fikry Nursyawal *, } \\
\text { Ari Widyati Purwantiasning }\end{array}$ \\
\hline
\end{tabular}

a. Kendaraan bermotor.

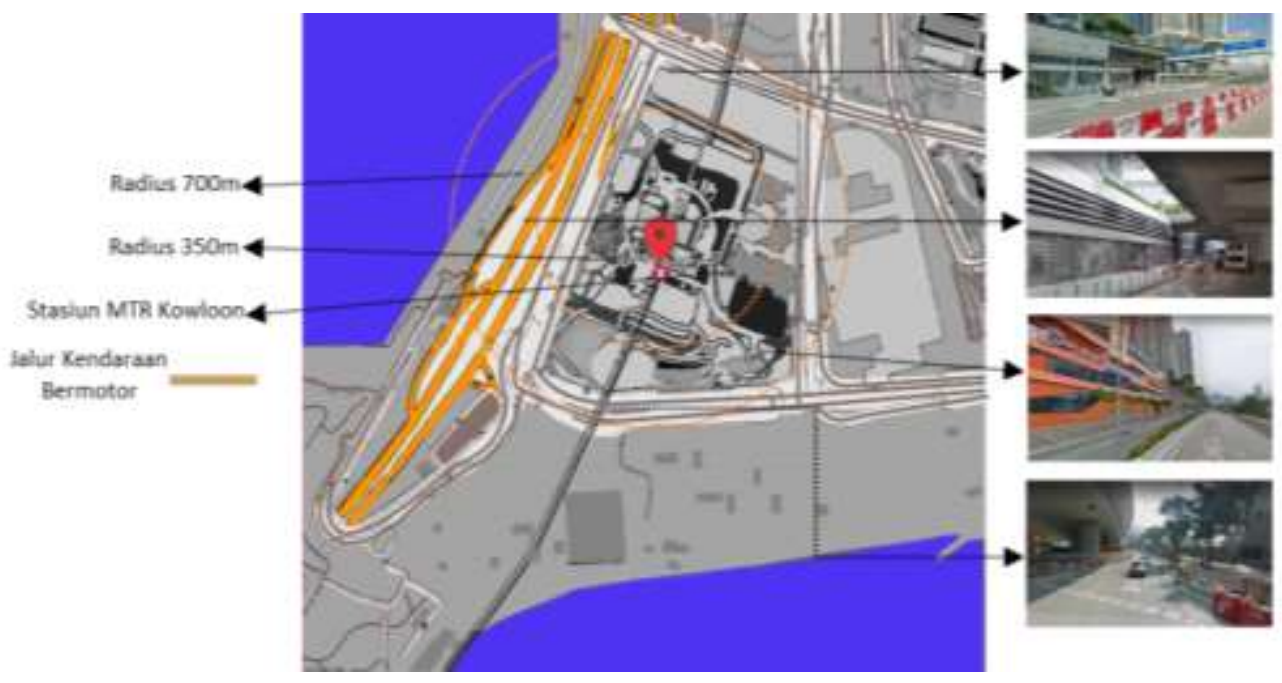

Gambar 3. Peta Jaringan Jalan Kendaraan Bermotor Kawasan Kowloon Sumber: Dokumen Pribadi

Pada gambar 3, dapat terlihat jalur jalan yang dapat diakses menggunakan kendaraan bermotor. Jaringan jalan untuk kendaraan bermotor juga merupakan jaringan jalan untuk transportasi bus.

b. Jalur pejalan kaki (pedestrian)

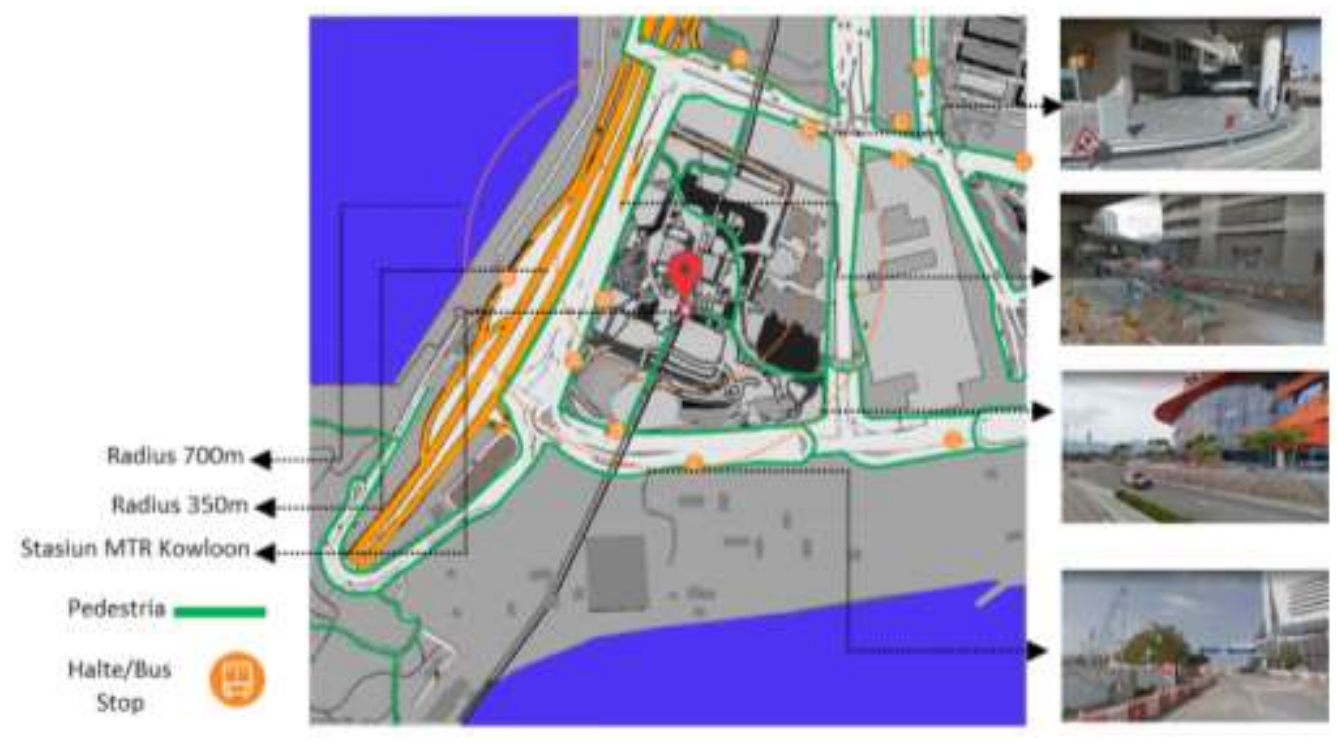

Gambar 4. Peta Jaringan Jalan Pejalan Kaki (Pedestrian) Sumber : Dokumen Pribadi

Pada gambar 4, dapat terlihat jalur-jalur yang dapat diakses oleh pengguna dengan berjalan kaki di kawasan Kowloon. 


\begin{tabular}{r|r|} 
Kajian Konsep Linkage pada Kawasan TOD & $\begin{array}{r}\text { Muh Fikry Nursyawal *, } \\
\text { Ari Widyati Purwantiasning }\end{array}$ \\
(Transit Oriented Development) West Kowloon, Hong Kong
\end{tabular}

c. Jalur sepeda

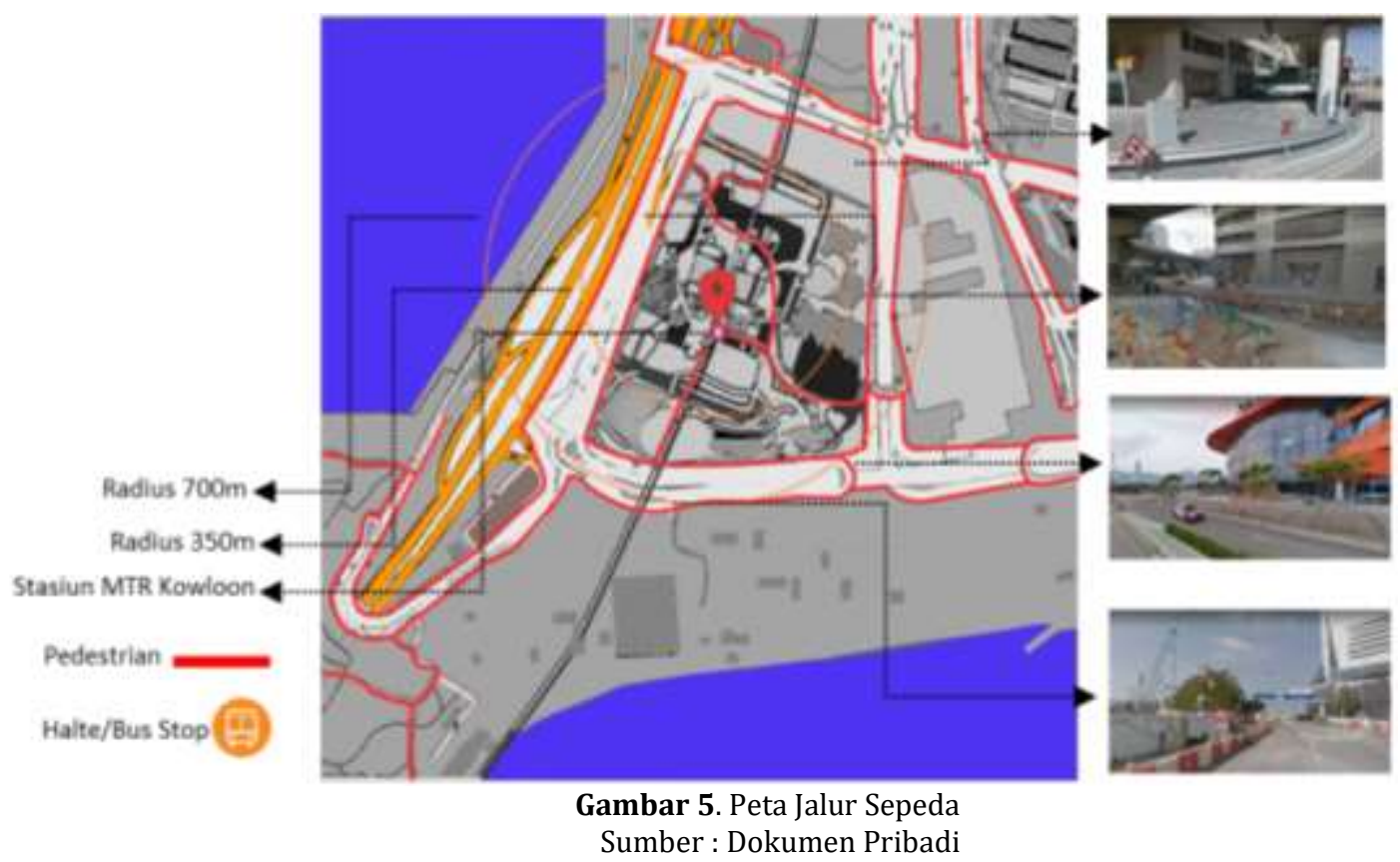

Pada gambar 5, dapat terlihat jalur atau jaringan jalan yang hanya dapat diakses oleh sepeda atau dengan kata lain kendaraan non-motor pada kawasan Kowloon.

\section{Jaringan Transportasi Umum}

Pada kawasan Kowloon terdapat beberapa jaringan transportasi umum yang dapat menjadi opsi untuk masyarakat pengguna untuk beraktivitas, diantaranya MTR (mass transit railway), Airport express (kereta bandara), Busway dan Airport Bus. Berikut merupakan pemetaan jaringan transportasi di atas.

a. MTR (Mass Transit Railway) dan airport express.

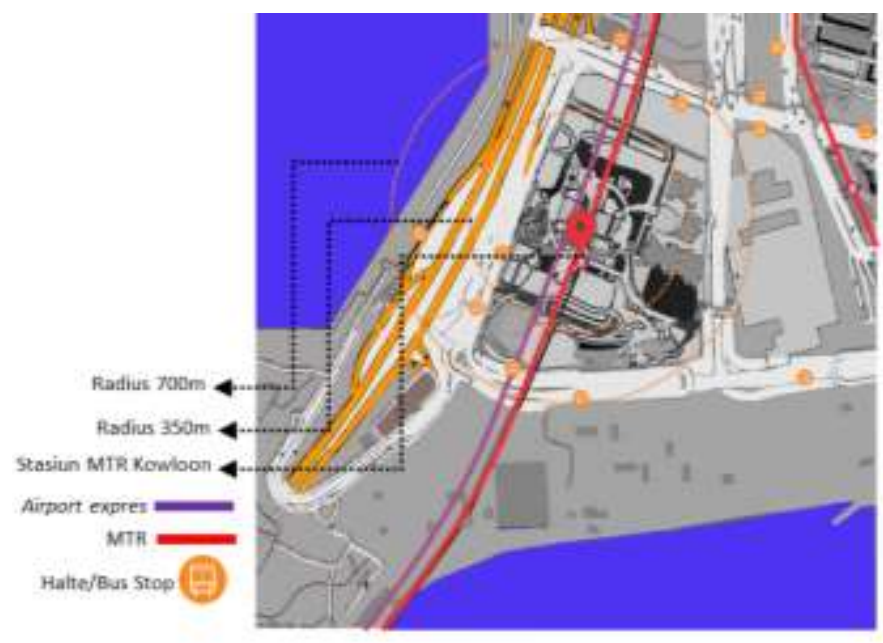

Gambar 6. Peta Jalur MTR \& Airport expres Sumber : Dokumen Pribadi 

Ari Widyati Purwantiasning

Pada gambar 6, dapat terlihat jalur transportasi umum MRT (warna ungu) dan Airport expres (warna merah).

b. Transportasi Busway

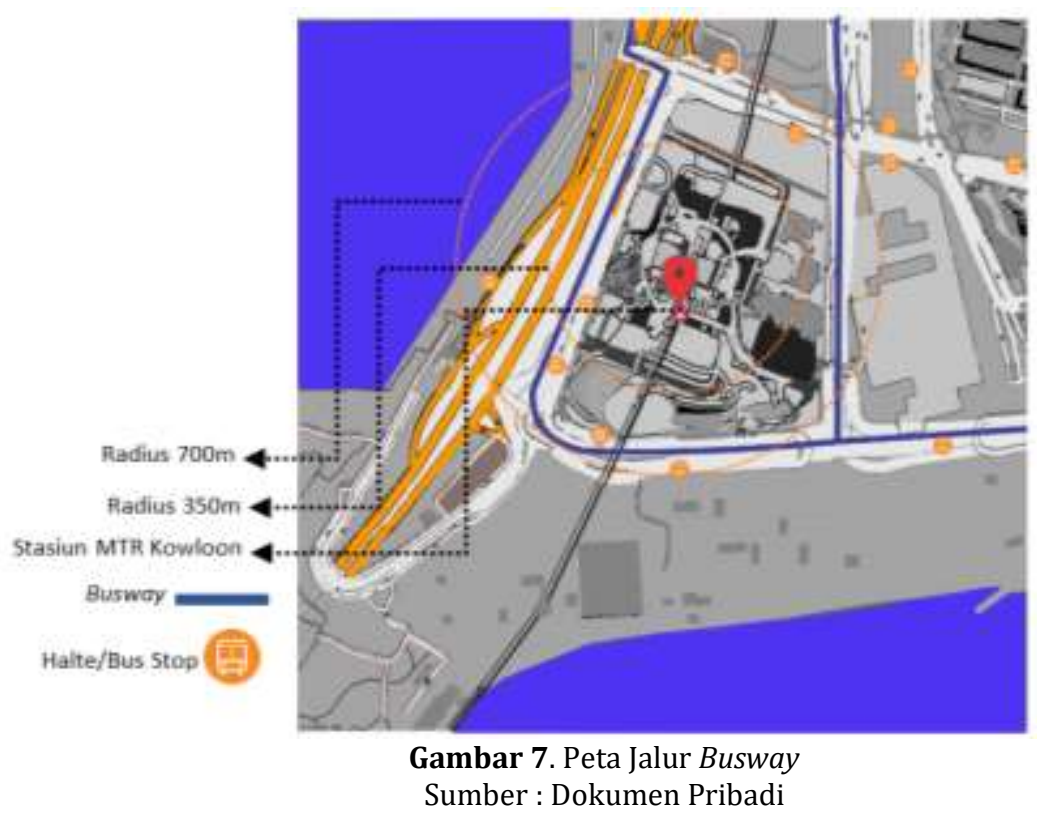

Pada gambar 7, dapat terlihat jalur transportasi umum busway di Kawasan Kowloon.

c. Airport Bus

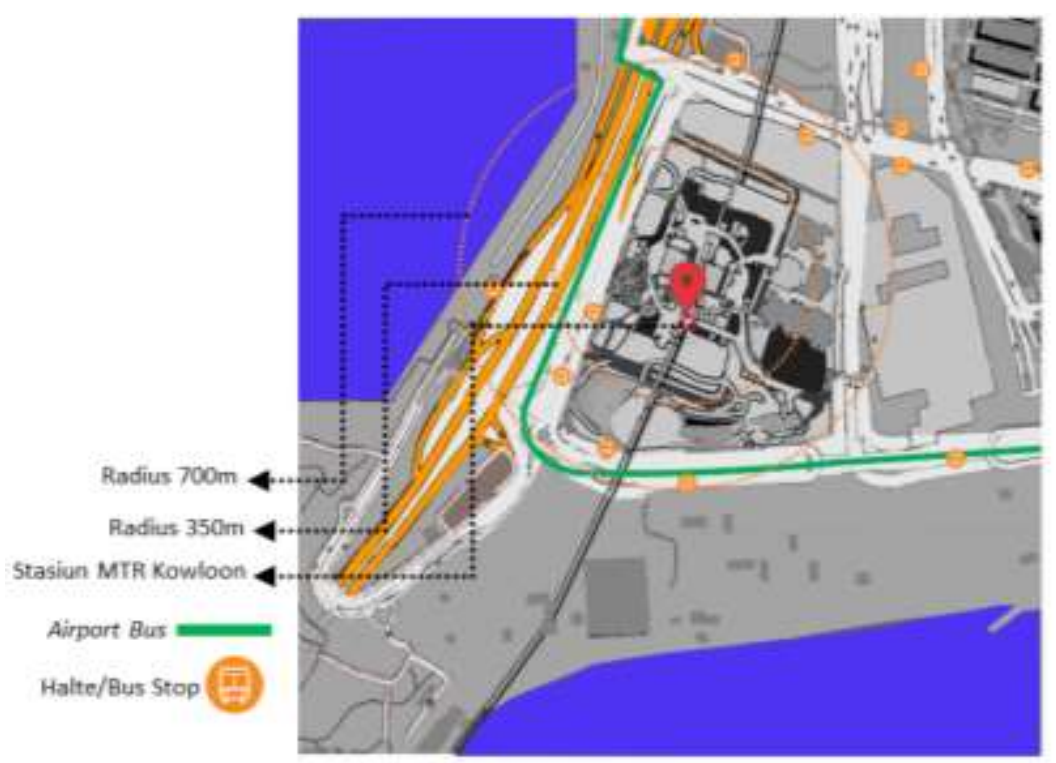

Gambar 8. Peta Jalur Airport Bus Sumber : Dokumen Pribadi

Pada gambar 8, dapat terlihat jalur Airport bus merupakan jalur jaringan transportasi umum. 


\section{B. Analisis linkage visual kawasan TOD Kowloon, HongKong.}

Berdasarkan data primer dan data sekunder yang sudah diperoleh, linkage visual terbagi menjadi 5 bagian dianalisis yaitu, linkage visual line (garis), visual corridor (koridor), visual axis (sumbu), visual edge (sisi), visual rythm (irama).

\section{Linkage visual line (garis).}

Linkage visual line (garis) merupakan elemen garis yang menghubungkan dua tempat secara langsung dengan deretan massa yang memiliki massivitas. Deretan massa dapat merupakan pepohonan, bangunan dan massa sejenis yang memiliki massivitas. Berdasarkan data yang sudah diperoleh dari kawasan TOD Kowloon dan kemudian dibandingkan dengan teori yang sudah diperoleh, terdapat linkage visual garis yakni berupa massa pepohonan yang menghubungkan Sky 100 Building dengan West Kowloon Cultural District.
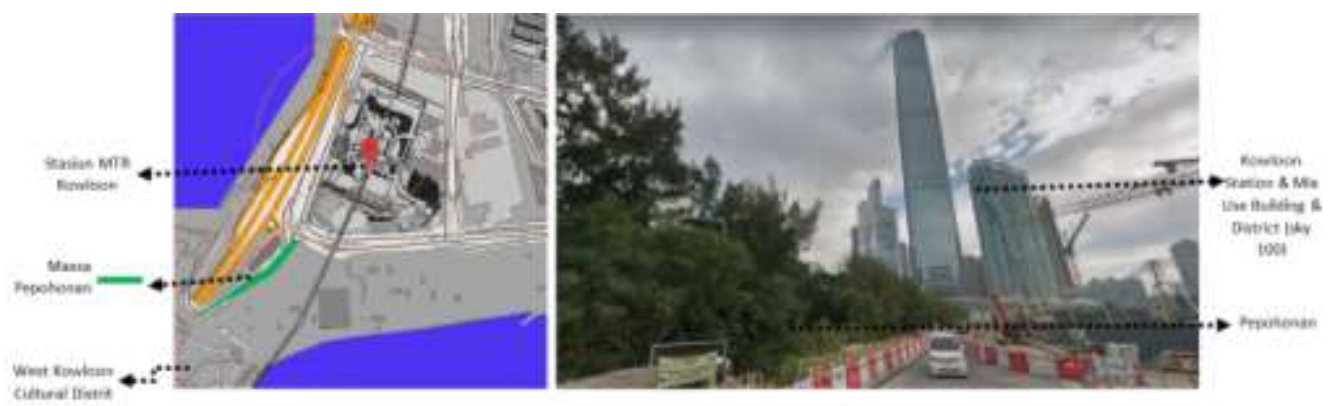

Gambar 9. Linkage Visual Line (garis) Sumber : Dokumen Pribadi

Pada gambar 9, terlihat hubungan visual line yang menghubungkan dua tempat dengan massa penghubung deretan pepohonan yang memiliki massivitas.

\section{Linkage visual corridor (koridor)}

Linkage visual corridor (koridor) merupakan linkage visual yang dibentuk dari dua deretan massa yang membentuk suatu ruang. Deretan massa dapat berupa bangunan, pepohonan, lampu jalan dan sejenisnya yang tentunya memiliki massivitas.
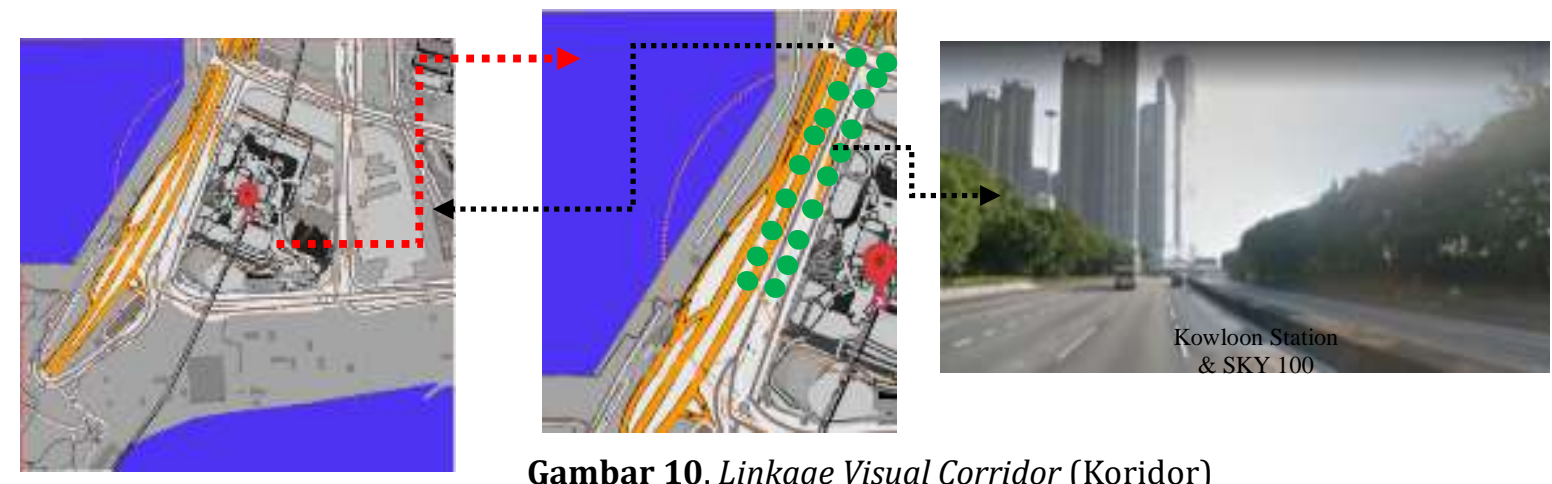

Gambar 10. Linkage Visual Corridor (Koridor)

Sumber : Dokumen Pribadi 
Berdasarkan data yang diperoleh pada objek studi kasus di kawasan TOD Kowloon menunjukkan bahwa pelabuhan Yau Ma Tei dan stasiun MTR West Kowloon \& Sky 100 Building terhubung oleh linkage visual corridor (koridor). Jalan tersebut terdapat pepohonan yang berjejer pada kedua sisi kiri dan kanan jalan yang membentuk sebuah ruang di antara pepohonan tersebut, oleh sebab itu, masyarakat pengguna dapat merasakan secara visual keterkaitan antara supermarket (carrefour) dan Poins Building

\section{Linkage visual edge (sisi)}

Linkage visual edge (sisi) merupakan Elemen sisi yang menghubungkan suatu kawasan dengan satu massa namun, tidak perlu diwujudkan dalam bentuk massa yang tipis seperti garis. Sama halnya dengan elemen garis (line), akan tetapi memiliki perbedaan yakni pada penetepan massivitas berada pada latar belakangnya. Kawasan TOD) West Kowloon berbatasan dengan Olympian City di sisi Utara, kawasan Austin pada sisi Timur, Breakwater di sisi Barat dan Victoria Harbour pada sisi selatan kawasan TOD West Kowloon. Berdasarkan teori dan pustaka yang diperoleh, massa linkage visual egde (sisi) yang menggabungkan dua kawasan tidak perlu terwujud dalam bentuk garis tipis namun bentuk massa tersebut harus memiliki bentuk yang berbeda dengan bentuk massa kawasan yang diperantarainya. Hal tersebut bertujuan untuk menjadi tanda transisi dua kawasan dan menjadi penghubung atau linkage yang mudah dipahami oleh masyarakat pengguna kawasan.

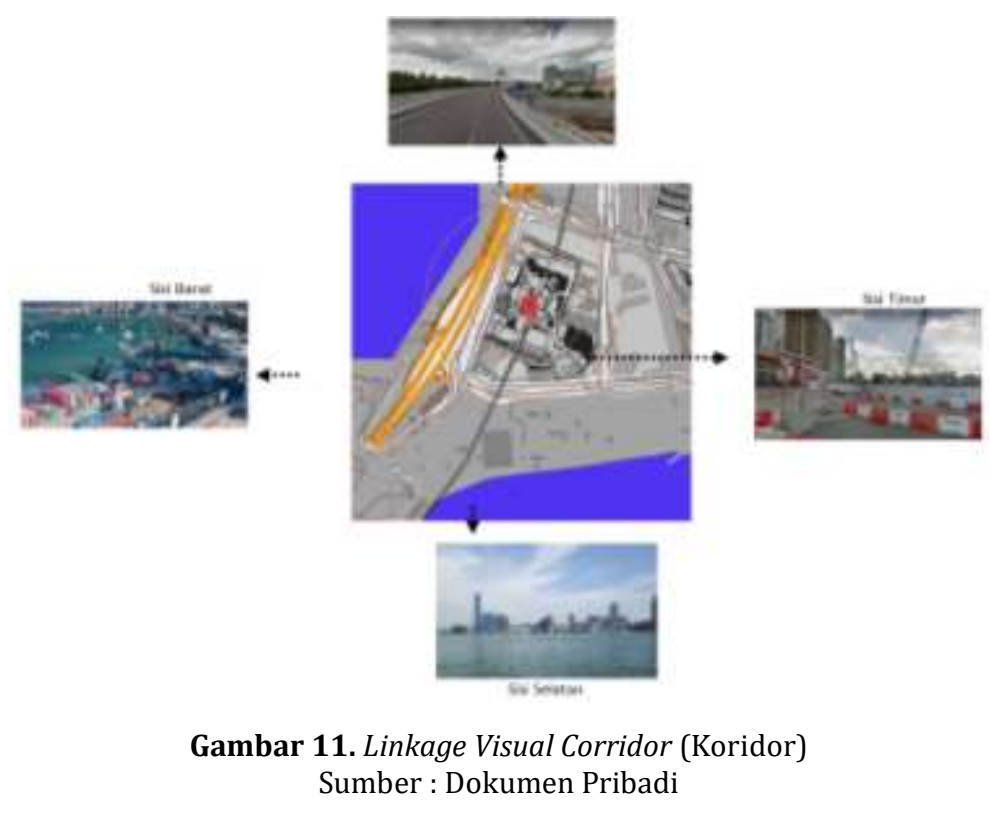

Pada gambar 11, menunjukkan kawasan-kawasan yang berbatasan dengan kawasan TOD West Kowloon. Linkage visual edge merupakan linkage yang menghubungkan dua kawasan 


\section{Kajian Konsep Linkage pada Kawasan TOD (Transit Oriented Development) West Kowloon, Hong Kong \\ Muh Fikry Nursyawal *, Ari Widyati Purwantiasning}

dengan satu massa. Oleh karena itu peneliti menganalisis linkage visual edge (sisi) pada sisisisi perbatasan kawasan West Kowloon.

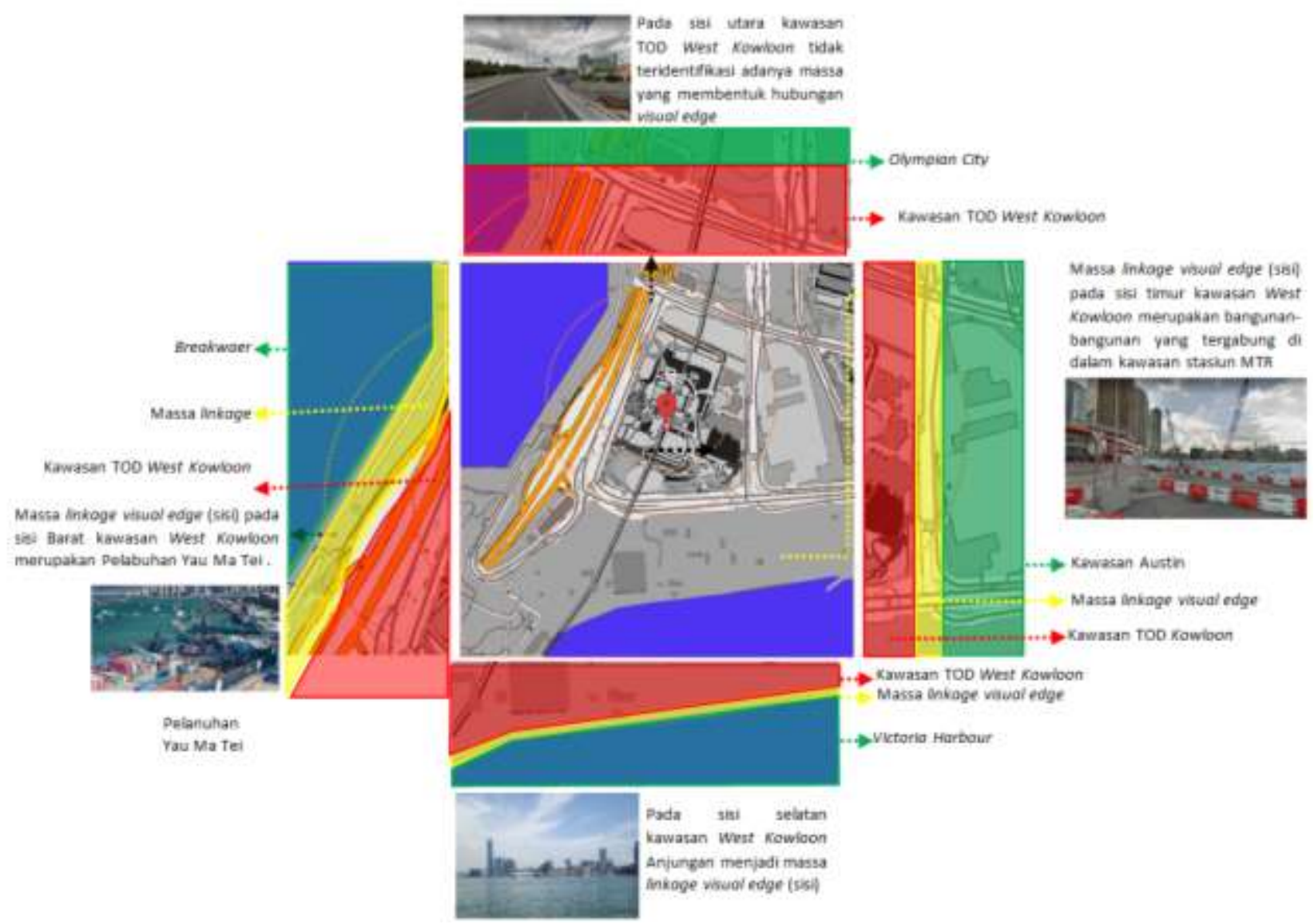

Gambar 12. Identifikasi Linkage Visual Edge (Sisi) Sumber : Dokumen Pribadi

Pada gambar 12, terlihat identifikasi massa yang menjadi elemen penghubung antar kawasan. Berikut di bawah ini merupakan tabel analisis yang dibuat berdasarkan identifikasi massa linkage visual edge (sisi).

Tabel 1.1 Analisis Linkage Visual Edge (Sisi)

\begin{tabular}{|c|c|c|c|c|c|}
\hline No. & Sisi & $\begin{array}{c}\text { Batas } \\
\text { Kawasan }\end{array}$ & Massa & Analisis & Gambar \\
\hline 1. & Utara & $\begin{array}{c}\text { Olympian } \\
\text { City }\end{array}$ & - & $\begin{array}{l}\text { Pada sisi Utara kawasan TOD West } \\
\text { Kowloon tidak teridentifikasi adanya } \\
\text { massa yang membentuk visual edge } \\
\text { karena tidak adanya massa yang } \\
\text { memenuhi kriteria visual edge. }\end{array}$ & \\
\hline 2. & Selatan & $\begin{array}{l}\text { Victoria } \\
\text { Harbour }\end{array}$ & Anjungan & $\begin{array}{l}\text { Linkage visual edge (sisi) pada sisi } \\
\text { selatan kawasan West Kowloon } \\
\text { terhubung oleh massa Anjungan yang } \\
\text { berhubungan langsung dengan } \\
\text { Victoria Harbour sehingga dapat } \\
\text { menimbulkan keterkaitan yang baik. }\end{array}$ & \\
\hline
\end{tabular}




\begin{tabular}{|c|c|c|c|c|c|}
\hline No. & Sisi & $\begin{array}{c}\text { Batas } \\
\text { Kawasan }\end{array}$ & Massa & Analisis & Gambar \\
\hline 3. & Timur & $\begin{array}{c}\text { Kawasan } \\
\text { Austin }\end{array}$ & $\begin{array}{l}\text { Bangunan- } \\
\text { bangunan }\end{array}$ & $\begin{array}{l}\text { Linkage visual edge (sisi) pada sisi } \\
\text { timur kawasan West Kowloon } \\
\text { memiliki massa berupa bangunan- } \\
\text { bangunan yang tergabung dalam } \\
\text { kawasan stasiun west Kowloon yang } \\
\text { memiliki eksistensi yang kuat karena } \\
\text { mudah terlihat sehingga menjadi } \\
\text { penghubung ataupun penanda yang } \\
\text { kuat. }\end{array}$ & $P=$ \\
\hline 4. & Barat & Breakwater & - & $\begin{array}{l}\text { Pada sisi Barat kawasan TOD West } \\
\text { Kowloon pelabuhan yang langsung } \\
\text { berhubungan dengan Breakwater } \\
\text { sehingga membuat hubungan yang } \\
\text { kuat. }\end{array}$ & 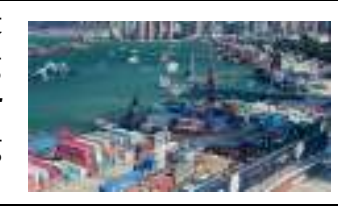 \\
\hline
\end{tabular}

Sumber : Dokumen Pribadi

e. Linkage visual axis (sumbu)

Linkage visual axis (sumbu) merupakan linkage yang menghubungkan dua tempat dengan mengutamakan atau menonjolkan salah satu tempat tersebut. Linkage visual axis (sumbu) bersifat spasial hampir serupa dengan linkage corridor (koridor) namun pada linkage visual axis mengutamakan hanya pada satu objek atau tempat. Linkage visual axis (sumbu) dapat diidentifikasi dengan melihat massa yang membentuk ruang dengan pola yang menuju pada suatu tempat. Massa dapat berupa bangunan dan pepohonan yang memiliki massivitas yang kuat dan dapat menjadi penanda yang mudah untuk dipahami secara visual atau dengan kata lain massa memiliki bentuk pola yang unik dari pada massa sekitarnya.

Berdasarkan data yang diperoleh pada objek studi kasus kawasan TOD West Kowloon, ditemukan beberapa tempat atau objek bangunan yang memiliki eksistensi sebagai ikon dari kawasan TOD West Kowloon. Pada gambar 13, terlihat tempat atau objek bangunan yang terdapat pada kawasan TOD West Kowloon. 


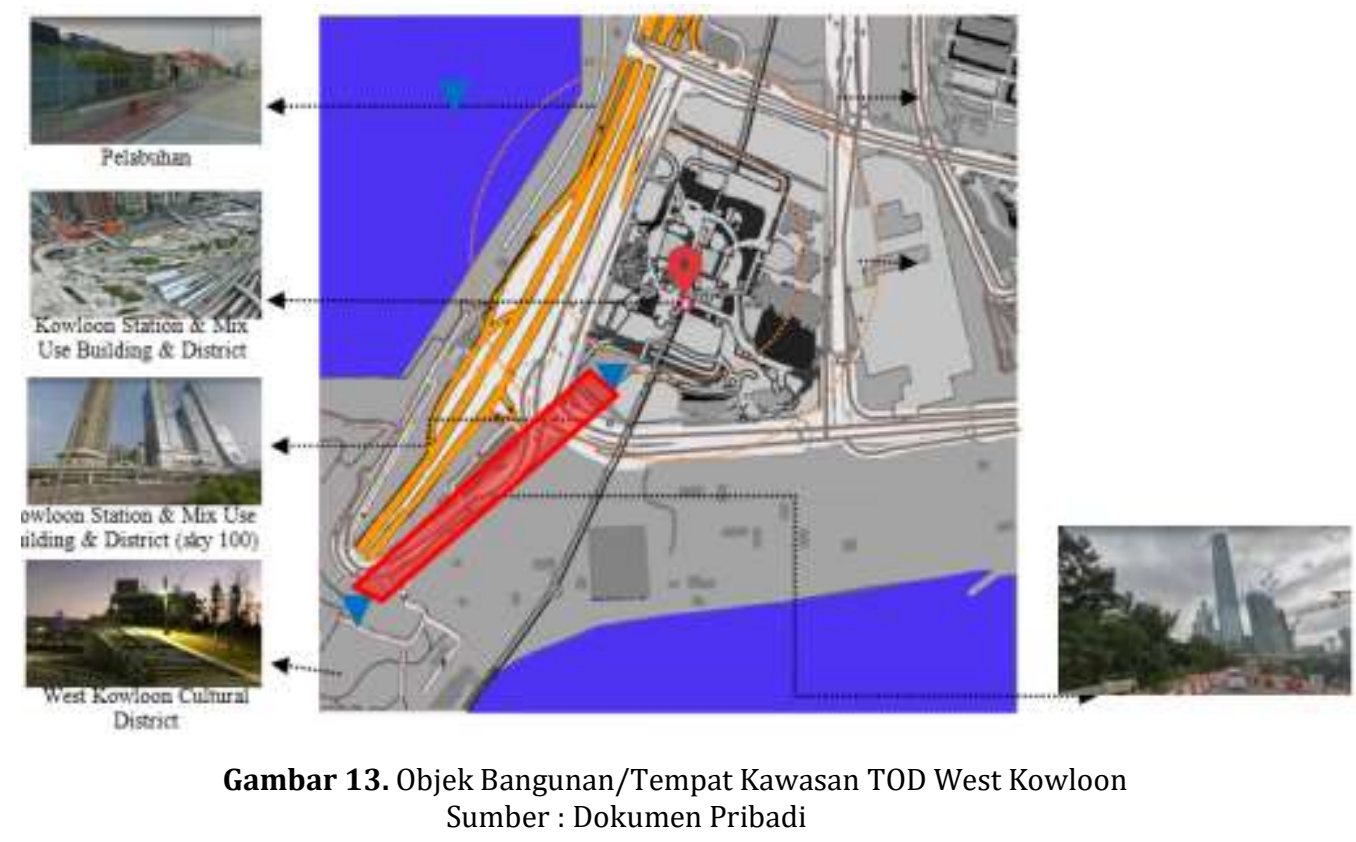

Berdasarkan data yang diperoleh mengenai objek bangunan yang ada, kemudian diidentifikasi objek bangunan yang memiliki keterkaitan atau hubungan secara visual axis (sumbu). Dari objek bangunan yang ada, hanya objek bangunan atau tempat West Kowloon Cultural District dan Sky 100 Building yang memiliki hubungan yang bersifat spasial yang terhubung oleh massa pepohonan dan memiliki keterkaitan satu sama lain. Sky 100 Building berorientasi menghadap ke arah West Kowloon Cultural District dan dihubungkan melalui massa pepohonan. Hal ini yang membuat hubungan secara linkage visual axis (sumbu) antara Sky 100 Building terhadap West Kowloon Cultural District dapat terlihat.

\section{f. Linkage visual rhythm (irama)}

Linkage visual rythm (irama) merupakan linkage yang menghubungkan dua tempat atau objek dengan massa dan ruang yang memiliki varian/variasi massa dan irama. Massa dapat berupa bangunan atau pepohonan. Elemen visual ini dapat terlihat pada fasad bangunan, ketinggian bangunan, susunan bangunan dan lain sebagainya yang tentunya memiliki variasi massa dan irama pada objek massa tersebut. Selain memiliki variasi dan irama, massa bangunan memiliki keunikan massa yang berbeda dari massa yang lainnya. Hal ini bertujuan agar hubungan suatu tempat atau objek dapat dengan mudah dipahami atau terlihat. 

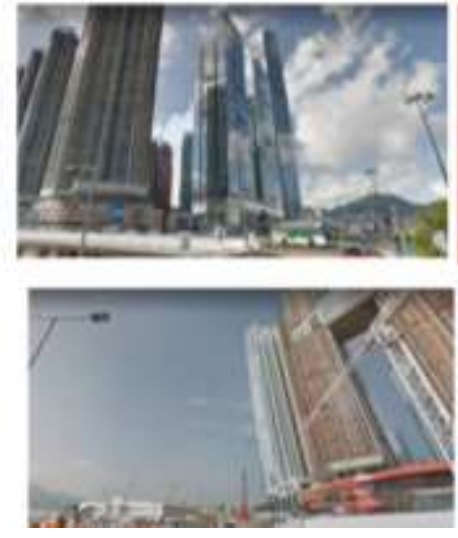

Gambar 14. Tipologi Fasad dan Ketinggian Bangunan Kawasan West Kowloon Sumber : Dokumen Pribadi
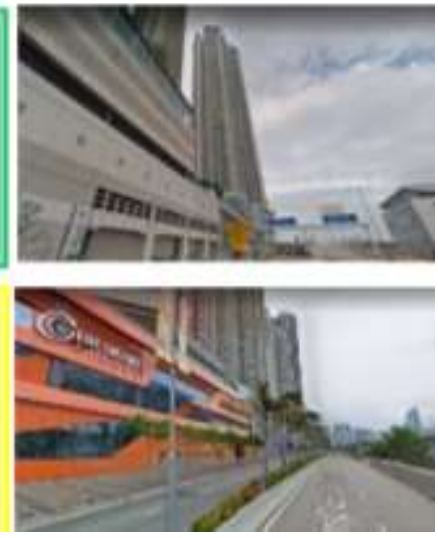

Pada gambar 14, terlihat tipologi fasad atau muka bangunan dan ketinggian bangunan. Peneliti mengambil data tipologi bangunan yang berada pada jalur utama pada kawasan TOD West Kowloon. Berikut merupakan penjelasan analisis terhadap tipologi bangunan yang kemudian akan dikaitkan dengan konsep linkage visual rythm (irama). Berikut ini, tabel analisis terhadap tipologi bangunan yang kemudian akan dikaitkan dengan konsep linkage visual rythm (irama).

Tabel 2. Analisis Terhadap Tipologi Bangunan

\section{Dokumentasi Eksisting Maps}
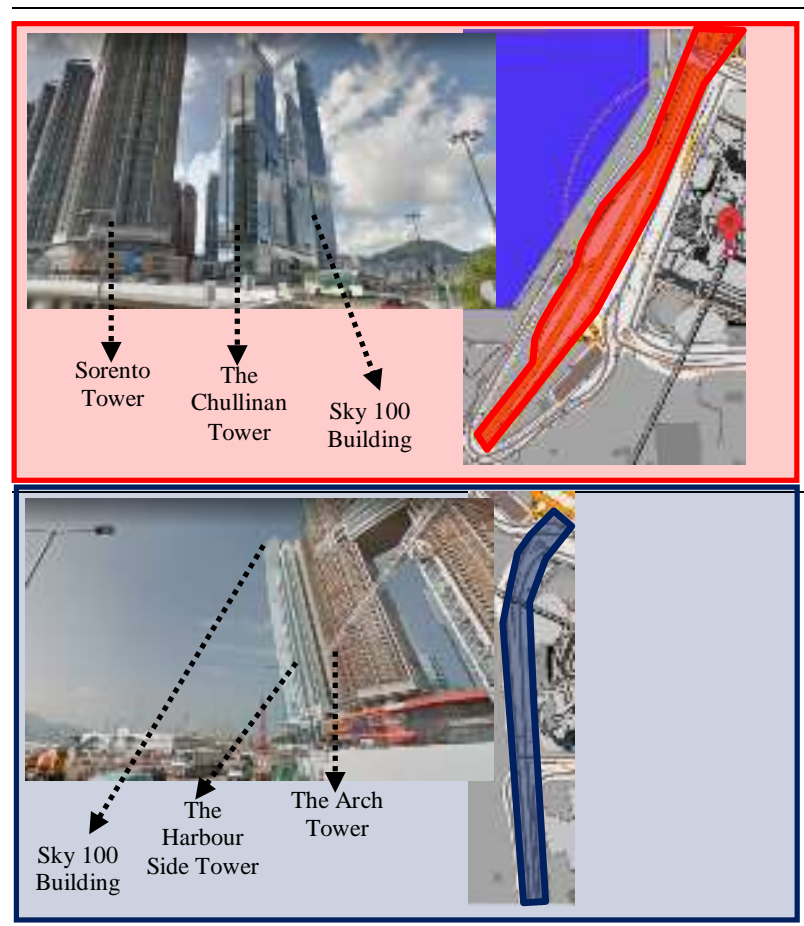

\section{Analisis}

Tipologi bangunan pada jalur merah memiliki irama ketinggian bangunan antara Sorento Tower (rendah), The Chullinan Tower (Sedang), Sky 100 Building (Tinggi). Hal ini membuat hubungan atau keterkaitan secara linkage visual rythm (irama) mudah untuk dipahami.
Tipologi bangunan pada jalur biru memiliki irama pada ketinggian bangunan antara bangunan The Arch Tower (rendah), The Harbour Side Tower (sedang), dan Sky 100 Building (tinggi). 


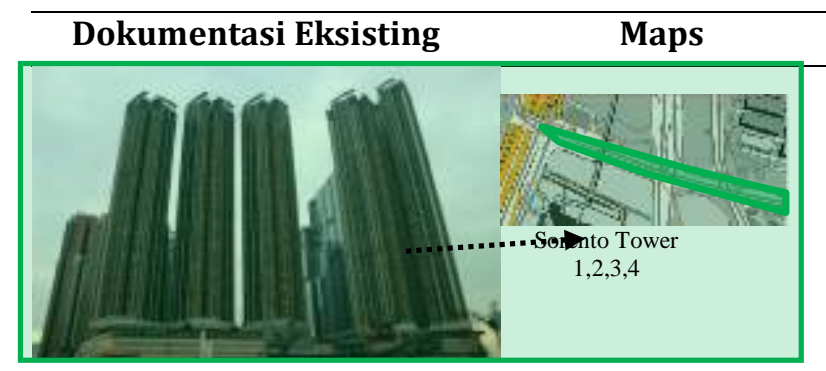

Tipologi bangunan pada jalur hijau memiliki pola dan bentuk fasad yang sama, yakni pada bangunan Sorento Tower 1,2,3,4, dan 5. Hal ini membuat hubungan secara linkage visual rythm (irama) dapat dirasakan pada jalur ini.

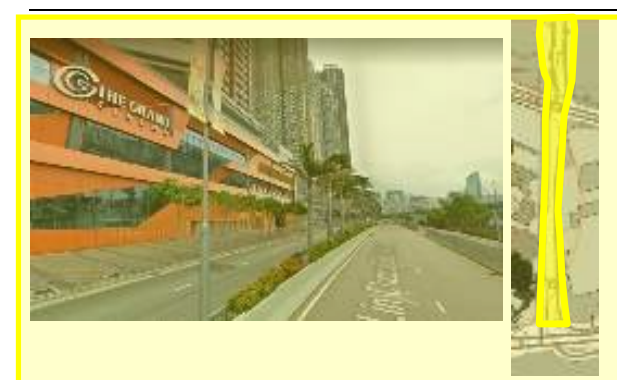

Tipologi bangunan pada jalur kuning ini memiliki ketinggian bangunan yang tidak berirama dan pola fasad yang juga tidak memiliki variasi atau pola yang saling terhubung, oleh karena itu hubungan seca linkage visual ryhtm (irama) pada jalur ini sulit untuk dipahami ataupun dirasakan secara visual

Sumber : Dokumen Pribadi

\section{KESIMPULAN}

Konsep linkage visual dalam implementasinya pada kawasan TOD (transit oriented development), memiliki peran penting dalam menunjang prinsip-prinsip kawasan TOD. Elemen-elemen linkage visual memberikan penjelasan secara visual terhadap masyarakat pengguna pada kawasan TOD. Elemen-elemen linkage visual yakni visual garis, koridor, sisi, sumbu, dan irama juga dapat mempertegas jalur sirkulasi atau pergerakan di dalam kawasan TOD. Elemen linkage visual sangat berkaitan dengan komponen-komponen kawasan TOD dan oleh karena itu perencanaan suatu kawasan TOD harus memperhatikan sinergitas antara elemen-elemen linkage visual dan komponen-komponen kawasan TOD.

Pada perencanaan suatu kawasan TOD konsep linkage merupakan poin penting yang tidak boleh terlewatkan. Hal tersebut dikarenakan konsep linkage memiliki peran sebagai "guide" atau pengarah dan penghubung. Pengarah yang dapat memudahkan masyarakat pengguna pada kawasan TOD dalam beraktivitas dan linkage visual juga berperan sebagai penghubung objek-objek bangunan yang ada pada suatu kawasan TOD. 


\section{DAFTAR REFERENSI}

Arsyad, Muhammad Afif, and Ketut Dewi Martha Erli Handayeni. 2018. "Pengukuran Kesesuaian Kawasan Transit Blok M, Jakarta Terhadap Kriteria Konsep TOD (Transit Oriented Development)." Jurnal Teknik ITS 7 (1). https://doi.org/10.12962/j23373539.v7i1.29865.

Bachtiar Arief, Andi, M Isran Ramli, Arifuddin Akil, and Ananto Yudono. 2015. "Prinsip-Prinsip Transit Oriented Development (TOD) Pantai, Berbasis Potensi Pelabuhan Rakyat Kayu Bangkoa, Makassar.” Universitas Hasanuddin. Universitas Hasanuddin, no. 124: 47-54.

Djokomono, Imam, and Agung Murti Nugroho. 2000. "Identifikasi Komponen Penting Kawasan Dengan Penerapan Tiga Teori Perancangan Kota, Studi Kasus Kawasan Jogonegaraan-Pajeksan." Media Teknik.

Firdaus, Fauzi, Ari Widyati Purwantiasning, and Lutfi Prayogi. 2018. "Revitalisasi Kawasan Kota Tua Jakarta Dengan Alternatif Konsep TOD." Purwarupa Jurnal Arsitektur 2 (1): 35-44.

Jackson, John Brinckerkhoff. 1984. Discovering The Vernacular Landscape. London: Yale University Press.

Kostof, Spiro. 1991. The City Shapes, Urban Patterns and Meaning Through History. London: Thames And Hudson.

Nugroho, Cahyo Agung, Ari Widyati Purwantiasning, and Dedi Hantono. 2017. "Penerapan Teori Linkage Dalam Penataan Kawasan Wisata Pusaka Soekarno Di Blitar." Jurnal Purwarupa 1 (2): 29-34. https://jurnal.umj.ac.id/index.php/purwarupa/article/view/2829/2238.

Octarino, Christian Nindyaputra. n.d. "Pengembangan Kawasan Permukiman Suburban Berbasis Transit Oriented Development ( TOD )," 135-44.

Priadmaja, Adji Prama, Anisa, and Lutfi Prayogi. 2017. "Penerapan Konsep Transit Oriented Development (TOD) Pada Penataan Kawasan Di Kota Tangerang.” Purwarupa Jurnal Arsitektur 1 (2): 53-60.

Raniasta, Yohanes Satyayoga, Ikaputra, and Dyah Titisari Widyastuti. 2016. "Pengembangan Kawasan Stasiun Tugu Yogyakarta Berbasis Transit Dengan Pendekatan Aksesibilitas." Jurnal Penelitian Transportasi Multimoda 14/No. 01/: 41-54.

Sugiyono. 2006. Metode Penelitian Kuantitatif Kualitatif Dan R\&D. Bandung: Alfabeta.

Toding, Kosmas, M Yamin Jinca, and Shirly Wunas. n.d. "Sistem Transit Oriented Development ( Tod ) Kereta Api Komuter Mamminasata System Transit Oriented Development ( Tod ) Railways Systemin The Plan of Mamminasata 'S Commuter Railways."

Trancik, Roger. 1973. Finding Lost Space.

Umanailo, Hamdi, Kota Universitas, Sam Ratulanggi, Staf Pengajar, Jurusan Arsitektur, Universitas Sam, Ratulangi Manado, and Penjara Tua. n.d. "Faizah Mastutie."

Yin, R. K. 2004. Studi Kasus : Desain \& Metode. Jakarta: Raja Grafindo Prasada. 